\title{
UNDERSTANDING 'EdUCATION FOR AlL' IN Contexts of Extreme Poverty: EXPERIENCES FROM BURKINA FASO ${ }^{1}$
}

\author{
Guillaume Charvon, \\ ATD Fourth World-US \\ Elaine Chase ${ }^{\mathrm{a}}$ \\ University College London
}

\begin{abstract}
This paper examines the meanings attached to Education for All from the often ignored or misunderstood perspectives of people living in extreme poverty. Allowing people to voice their own understandings of the difficulties they face offers new insights into the essence of the tension between the worlds of reproduction and innovation and the possibilities of achieving harmony between them. Community meanings attached to Education for All were explored by way of a major participatory, action-oriented research project conducted in contexts of poverty in Burkina Faso. The study noted that the experience of poverty and famine influence the value that parents and children attached to formal education, and therefore their interest and ability to engage with it. Community-based education, for example, helped to reproduce knowledge associated with day-to-day living and achieving, at least, a basic livelihood. Formal schooling, on the other hand, was associated with developing new understandings and ambitions, yet also distanced children and young people from local knowledge, social networks and sources of support often needed if the outcomes of schoolbased education did not lead to improved livelihoods.
\end{abstract}

Keywords: Education for All, merging of knowledge, extreme poverty, world of reproduction, world of innovation

\section{Introduction}

Children who go to school don't know how to grow things anymore, and there aren't enough offices for everyone, so what are we going to do?

As the Millennium Development Goals (United Nations, 2000) ended theirtermin 2015, the second of these goals, universal primary Education for All, has posed particular challenges for countries with limited resources and where other complex social, cultural, economic and logistical constraints limit access to and participation in education. Education for All poses, therefore, complex questions about the meaning and value of education in societies facing extreme poverty and famine.

The United Nations human development index ranks Burkina Faso as 183 out of 187 countries globally, with 84 per cent of its population estimated as living in poverty according to the Multidimensional Poverty Index (UNDP, 2013). Food scarcity and famine are major challenges, and in 2012 the country was ranked 46 out of 76 on the global hunger index (World Food Programme, 2013). Famine is the result of a cumulation of natural disasters such as drought, floods and locusts which have led to increased desertification and reduced access to water and pasture land. Its land-locked position means that the country is also vulnerable to economic shocks such as sudden hikes in food prices which limit access to affordable food for the vast majority of people.

a Correspondence can be directed to: e.chase@ucl.ac.uk 
Within two or three generations, Burkinabe society has seen itself caught between two worlds: the world of reproduction - an agrarian/pastoral way of life; and the world of innovation - urban life, offering alternatives to the scarcity of arable land, and to which are attached certain ideas of social and economic success and well-being (such as access to electricity, running water, among others). The attractions of the latter have resulted in large demographic shift and rapid social change accompanied by a growing tension between these two different ways of life. Like other countries in sub-Saharan Francophone Africa, educational researchers in Burkina Faso have observed this tension reflected in the gap between the realities of family life and what children learn at school. One of the consequences of this disconnect is the perception that community life is not valued and that children who attend school seek ultimately to distance themselves from their family and their surroundings. Equally, parents may stop sending children to school, evidenced by the fact that the mean duration of school attendance for adults is just 1.3 years (UNDP, 2013).

The generalized precariousness of life in terms of health, nutrition and access to water and education forces families to try and broker a balanced relationship between two modes of life with vastly different value systems: on the one hand a world structured by urbanization, increasing individualization and modernity; and on the other hand rural life, underpinned by notions of community and tradition. The contradiction between the school and the home environment outlined above is rooted in the difference between these different worlds and the sorts of knowledge required to exist and survive in each of them.

This paper highlights the educational challenges for a societyin transition from the often ignored or misunderstood perspectives of people living in extreme poverty. Allowing people to voice their own understandings of the difficulties they face offers new insights into the essence of the tension between the worlds of reproduction and innovation and the possibilities of achieving harmony between them. The paper begins with a brief overview of the origins of action research and its methodology. It then goes on to present some of the key findings from the research before discussing their implications for the question of Education for All in Burkina Faso and beyond.

\section{Methodology}

In the social sciences, action research is characterized by its transformative impact on the reality of the subject of its investigation, and by the production of new knowledge about this reality (Freire 1972, 1974). The action research methodology employed in the current project was inspired by the transversal approach developed by Rene Barbier within his body of work on existential action research (1996). A fundamental principle underpins the method - the need to begin with people's own knowledge and expertise and not from an assumption of their ignorance. A wooden plaque displayed at the Burkina Faso headquarters in Ouagadougou captured this philosophy:

\section{Let Those Who Think They Don't Know Anything Teach Those Who Think They Do}

The methodology works from the understanding that people with the most essential knowledge are those who struggle to make ends meet in the most difficult circumstances. It encompasses a radically different approach to orthodox social science in that it aims to produce knowledge with people rather than about them. Action research of this type incorporates two methodological components - sharing knowledge and recognizing knowledge. Combined, these lay the basis for reconciling knowledge, which, as we will see later, helps bridge the gap between the world of reproduction (tradition) and the world of innovation (modernity).

The action research project was carried out over a period of 18 months, involving 335 men, women and children in urban and rural settings across Burkina Faso. The fundamental question underpinning the research was: What knowledge do we need to build a future for everyone? The topic relates directly to the meaning of Education for All in a country like Burkina Faso. 
The work culminated in a seminar that took place during the first quarter of 2013 in Ouagadougou and involved 65 participants from Belgium, Central African Republic, Ethiopia, France, Great Britain, Mali, Senegal and from all the provinces of Burkina Faso. Participants were drawn from very different backgrounds and with different family, communal, professional or institutional responsibilities. While some had a university education, others had never picked up a pen; and while some had spent their lives working the land, others had never pulled a weed.

Findings from the wider research programme were incorporated into a process of knowledge sharing, which ensured that the ideas of those most likely to be excluded are placed at the heart of these interactions. The focus is on the reciprocal value of knowledge brought about through a permanent dialogue between community knowledge, expressed by those living in marginalized communities, and the knowledge of books and educational institutions. The transmission of knowledge is not structured on the idea of one-way exchange but on a dynamic of mutual and collective learning which assumes the fragmented nature of knowledge - no single person can know everything. Knowledge emerges as a collective construction carried out through three critical stages to which each person is able to make his or her contribution.

Time was first spent working and reflecting together in distinct groups made up of (a) representatives of national and international institutions, non- governmental organizations (NGOs) and universities; (b) those working in the field of education or related areas; and (c) families living in poverty and activists that work alongside them. This first stage is when each participant becomes conscious of the value of his or her life experience. Those living in extreme poverty and having been subjected to discrimination realize that everyone, not just those in poverty, shares the same goal of eradicating misery. Once this condition is in place, those in poverty can say things that would normally remain unspoken. As one young mother put it:

Often, when I speak, I want to say certain things but the problem is that other thoughts come to me. Often when problems come into my head like that, I prefer not to say anything. I just let it go. ${ }^{2}$

The second critical stage consists of validating the legitimacy of each person's knowledge in peer groups. This enables each participant to move from the individual life experience towards constructing knowledge through dialogue with those people whose life experiences have forged similar understandings of the world to their own. The third stage is when the knowledge generated within the peer group is endorsed more widely and becomes recognized as established knowledge. This third stage is dialectic because it transmits the shared knowledge beyond the peer group to enrich other people's knowledge. From the point of view of action research, this wider exchangeenables agrowth in intelligence - that is, it enables participants to recognize how to expand the breadth of their understanding and ultimately to make valid judgements about the value of knowledge from other sources. Following are the themes that emerged from this work, both in terms of the process of research and its outcomes, which are relevant to the question of Education for All.

\section{The Relevance of Action Research to Education for All}

The research revealed how those in poverty often feel that their own knowledge is dismissed as false, as one participant put it, 'people in poverty have no truth because even if what they say is true, others don'tbelieveit'Thusaction research, through creating an environment in which people are recognized for the first time as speaking the truth, promotes cohesion and inclusion of those most likely to be marginalized in society.

Throughout the action research, a degree of unity emerged between vastly different groups concerning the fundamental knowledge underpinning their lives, irrespective of whether it was acquired in academic circles, through school, the community or directly from experience. Several crossroads in the process illustrated how action research has the potential to identify common ground and mutual understanding between people with very different experiences; those in poverty 
discover the value of their knowledge and skills and others recognize its worth. In this way everyone begins to have a say and to play their part in the shared struggle for humanity. One participant in the research told the following fable that illustrates this point:

One day in the bush, a chief invited all the animals to beat his millet. The elephant came and beat a lot of it. The buffalo managed to beat an impressive amount. Then the smallest of all frogs also joined in the work. Once all the work was done, the chief sent his supervisor to congratulate everyone. When he got to the two grains that the little frog had managed to beat, he became very angry and said, "Is that all you can do, you lazy creature!' And he immediately dragged him before the chief. In front of the chief the frog explained himself, 'I didn't refuse to work but here's my stick and here is my hand. My hand did what it could with the stick that it had'. The chief, who was a just man, congratulated the frog, 'the little frog did not refuse to beat the millet, he took part in the shared task, let's not exclude him by humiliating him'. And everyone clapped.

Through giving equal value to different types of knowledge, this type of participatory action research encourages everyone to review the judgements they make about themselves and others; those having experienced the depths of poverty and exclusion suddenly find themselves recognized as experts in their own right. So, there is a shift from certain knowledge being unappreciated and associated with humiliation, towards knowledge which is recognized and accompanied by a sense of pride and inclusion. This was alluded to by one participant in the following way:

I have had many difficulties in my life. What I have lived through is not easy but it is nobody's fault. Today, if it wasn't for my children I could say that everything is fine. If it wasn't for my sister wholives on the streets in town and who I worry about, I could declare that my misery is over. When I say my misery is over, what does that mean? It's because people I didn't know before, and even those that I did, have become closer to me. That's why I can say that my misery is over. I am now among people.

\section{Defining What Constitutes Knowledge}

Throughout the research, participants identified at least four different types of accumulated knowledge, central to influencing them through life: knowledge that imbued them with a sense of resistance; knowledge that empowered them to hope for a better life; knowledge that bridged the realities of their traditional lives with the social and professional demands of the modern world; and an awareness that knowledge could be destructive, creating a rupture between the self and community.

Knowledge of resistance was said to derive from the harshness of life experiences and enabled people to face the daily demands of extreme poverty and its associated exclusion:

If you have suffered in life, you will know how to behave, but for someone who has never had to struggle, they would find it hard to deal with that life. Misery gives you advice... There are people who criticize me because I am poor, because I wear the same clothes every day.... They are right but the problem is that these people live their lives in a way that doesn't allow them to be my friends.

Knowledge of empowerment was largely associated with formal education and its promise of a 'better life', for children and grandchildren. Such knowledge was directed towards the future, even if it meant making sacrifices in the here and now as exemplified by the thoughts of these parents:

Whatever misery you face, don't allow your children to live it, do everything you can to send your children to school. Nowadays, I thank God, I sell second hand shoes to 
make-do but sometimes it is really difficult for me. If I manage to pay school fees this year, I pray that I don't have a problem next year.

In May, I take my children out of school to work in the fields. I do this because we have to have enough to eat and to be able to send the children to school the following year.

Knowledge bridging traditional and modern worlds was often described in terms of the skills acquired and transmitted through generations and which inscribe a process of intergenerational learning of fundamental knowledge:

My father sent me to live with my very old aunt who has never been to school. But she gave me knowledge about becoming a woman for the future. She worked in the fields and sold produce at the market. I learned from her how to grow things, how to sell the crops, she advised me. At the age of seven I was doing the same work as my aunt. She taught me good behaviour. From her I learned about respect for others. She taught me how to bring up children.

Likewise, knowledge gained from living in the family and community was also considered empowering because it lays the basis for learning in school. For example the respect taught within the family was seen as essential as the basis for learning in school.

\section{Knowledge for a Divided Society}

A strong theme that emerged throughout the research was the extent to which the educational choices for the majority of parents living in poverty are polarized around the possibilities of enabling their children to belong to one of two worlds outlined earlier on in the chapter: the world of reproduction - the agricultural and pastoral way of life, based on imitation and repetition; and the world of innovation - linked to the emergence of individual gains, rapid social transformation and technological change. The educational choices that parents make for their children are determined by their understandings and perceptions of these worlds and how they define the future.

Yet these choices are further complicated by the fact that the value sets which organize and orientate these worlds are often incompatible with each other. Even the modes of teaching they each use are contradictory. The world of innovation supposes the creativity of each generation, while that of reproduction rests on the repetition of methods, ideas and ways of doing things, from one generation to the next. As one woman put it:

That [knowledge of reproduction] is the knowledge of everyone, the knowledge my mother gave to me and that I have passed on to my daughter, you can't get better than that. What didn't my mother tell me: how to grow things and grind wheat, how to fetch water and firewood, how to go to the market - my mother taught me all of that. If you accept what she taught us, you will see that one day you can do anything.... I myself learned to prepare by watching others do it and when I tried to do it, I could. I watched carefully because I knew that it would do me good.

School, the driver of the world of innovation, prioritizes the emergence of individuals while communitarian education, that of reproduction, situates the child in a social context where ' $l$ ' never usurps the 'we.' This subjection to the community, the driver of the world of reproduction, has less and less importance in the world of innovation. Hence success, whether shared or individual, only has meaning within specific contexts. What's more, the value systems on which these worlds are built are mutually exclusive and hence incompatible, explaining the disconnection suggested in the introduction to this chapter. Useful knowledge in one world is determined as useless in the 
other. If a child learns to grow crops, this knowledge has limited relevance if he or she identifies with an idea of success linked to city life. And conversely, theoretical knowledge gained in school may have no direct relevance to the realities of village life:

They say that if you don't go to school you won't have knowledge... but we know that there are those who did go to school and who don't have the knowledge that others have; and others who have not gone to school and who have knowledge.

Participants repeatedly reflected on how different understandings of knowledge influence wider processes of inclusion and exclusion. For example, school is uniformly presented as a tool for empowerment. Research in recent years in Burkina Faso (ATD Fourth World ,2004) has, however, shown how children who attended primary school but have been unable, usually due to family difficulties or lack of resources, to proceed to secondary school often end up living on the street; they fit neither in the world of reproduction nor in the world of innovation. Conversely, children who have rarely or never been to school often reconnect more easily with their families.

\section{The Meaning of Educational Success}

Participants' views about what signified educational success were inevitably tied to their own understandings of what constituted the most valid and useful knowledge for their daily lives. Nonetheless, the action research and the seminar generated some consensus concerning basic values which were vital for everyone to succeed in educational terms.

Solidarity and mutual support were seen as a fundamental pre-requisite for learning, especially incircumstances of extreme poverty. Onemanwhoearned his living through begging on the streets spoke of how when one of his children's friends came from school not having eaten, he took 100 CFA francs from his box and gave it to him, even though he did not know if he would have anything to give his own children that day. Another example was given of a child who had to repeat the first year of school five years in a row because his mother could not afford to pay the annual supplement of 1,500 CFA francs. The child started to become violent and alienated himself from others. The teacher offered to pay some of the contribution and the child was appointed as class prefect. Gradually he regained trust and confidence and was able to succeed.

Educational success was also thought to be reflected in values of respect, forgiveness, humility, courage and dignity not only for oneself but also for others. One girl said,

When my friends went off somewhere to eat and I had no money, I preferred to say that I wasn't hungry, rather than admit that my father had nothing to give me. That would show a lack of respect for him. I passed the BEPC [exam] with an empty stomach, but I didn't tell my friends that my father hadn't given me anything to eat, I said that I was too preoccupied by the exam to eat.

Success was also defined in terms of becoming useful to self, family, community and society as a whole. Those who became a reference point in their communities, who guided others and were consulted for advice, typified what it meant to be successful. This notion of educational success as being useful to oneself and others implies a sense of belonging to a community - being able to acquire knowledge, share it with others and then collectively put it into practice. As one participant put it:

Knowledge that is most important to me is being able to get people together so that those who know things teach those who don't, so that collectively we can exploit this 
knowledge. Nowadays we don't listen to those who are in poverty but we do listen to those who are better off. Yet those who don't have anything may sometimes have really good ideas for us. We have to do everything we can to listen to them.

Many participants defined the essence of knowledge not as the means for becoming 'master and possessor of nature' (Descartes 1637) but as the basis for belonging to a community of other humans. Knowledge makes sense when it creates cohesion within a community around a set of shared values. These values have to be learned and they constitute a body of knowledge in their own right, sustaining social ties and enabling people to live together in ways shaped byculture. From the perspective of those living in extreme poverty, this knowledge is fundamental because the security of existence and the ability to feel human amongst humans depends on it. This vision of educational success thus emerges as a project understood as discovering knowledge that unites society as a whole.

\section{Factors that Prevent Educational Success}

However, the achievement of this shared vision for educational success, grounded in the experience of community, was thought to be constantly challenged by the evolution of modern society, by the daily constraints imposed by extreme poverty and, as noted earlier, by a growing division within society into two separate worlds.

The research and the seminar during which the findings were discussed revealed several fundamentalfactors that got in the way of attainingeducational success. An absence of birth certificates for many children was a recurrent concern, onemotherdescribing thecertificateas'the first diploma of life' without which children could not be enrolled in schools. Others described long periods of sickness during which children could not attend school either because they were ill themselves or because they were caring for others who were ill.

Overcrowded classes and de-motivated teachers, the irrelevance of the school curricula and the hidden costs of education, such as the contributions for school meals or to the parent teachers associations, all created further barriers to accessing school for many. Yet there were also other social challenges described, such as discrimination, humiliation, mockery and violence, typically experienced by those in poverty (see Walker et al., 2013). One parent explained,

One day my daughter said to me, 'Papa, they told me at the school that it is pointless me studying and that I will never have my certificate because my father is poor. He empties the public toilets, he makes ropes in order to sell them.

And one young man describing his earlier experience of school said,

When I was in class it was hard. The teacher said to me, 'your mother can't buy you a school bag!' And they made fun of me. Some pupils were laughing. As I was only a child, I was ashamed and I often got angry. That's how violence begins.

Hunger and famine emerged as further challenges to learning for many children and their families. People spoke of how the climatic conditions of Burkina Faso often affected food production and generated sometimes extended periods of famine across the country. Hunger was said to affect the lives of communities living in poverty in a number of ways. At a very basic level, it made learning extremely difficult:

You get up, you have eaten nothing, you leave for school with a cramping stomach. Who is going to get up in the morning have a small bowl of millet and go to school? On top 
of eating the small bowl of millet, I think it is the efforts of our parents that are in our hearts. Our parent's efforts are like a meal, it was that which filled our stomachs so that we could carry on.

When my daughter went to school, our main worry was hunger, because it was hunger that was killing us. So we would send our child to school but a child can't learn if they are hungry.

Secondly, hunger was also considered to be central to the relationships between families living in extreme poverty and the communities they belong to. Hunger, it was said, generated such a powerful obstacle to educational success that it was possible to succeed only if families and communities pulled together. In reality, however, families were increasingly forced to choose between preserving their dignity and subjecting themselves to humiliation in order to survive. As one participant put it,

Sometimes they give us leftovers on dirty plates. It makes us feel bad, but what can we do?

More broadly, hunger was described as threatening the social bonds within communities. Families in extreme poverty were constantly posed with the dilemma of how to belong to a community when they had nothing to share. This concern was coupled with a profound sense that any collective responsibility for each other within communities was diminishing in modern society, as one participant put it;

Today, man has less pity in his heart. He only looks after his brother, his child and his wife. But if you are poor, you don't have a wife or a brother... who is going to look after you? And who are you going to look after?

\section{The Meaning of Education for All}

The wider question concerning what Education for All means in a country like Burkina Faso is illustrated by the following quote from one participant in the research:

If educational success is to work in offices or be a politician, I can say that amongst the poor, those who succeed are very few. That is why so many families living in poverty stop sending their children to school. That is why I suggest that at school they also teach children training in how to do things. If they did that, then we could believe that school is for everyone.

In effect, parents are often forced to take a gamble over which world their children should stake a claim to, a gamble which has several consequences. First, it results in parents choosing to assign their children to different worlds. Within the same family, some will go to school while others will stay and learn about agricultural and pastoral life. Since success is understood collectively rather than on an individual basis, the chances of success for the whole family are thus increased through the diversity of the choices made.

The demands for children to fit into either one world or the other generate a major stumbling block for policies concerning Education for All. It's not a lack of understanding on the part of the school about how to enlighten parents which undermines such policies, but rather their rational underlying value system. At the heart of the world of reproduction, socio-economic success is concentrated within the family to enable them to face the precariousness of the family's existence. Does it make sense, therefore, to choose a single pathway towards success for all while the future of the whole community depends on it? After all, the pathway that takes children through school and leads to regular paid activity in town is just as precarious and is no more likely to offer security. Taken 
within this reference system, choices made by parents are logical and rational, emanating from the sense of collective determinism at work within the world of reproduction. Hence as one parent put it, 'of my nine children, two are going to school, the girls are going to learn about work within the family, the others will look after the cattle in the fields.'

Yet, from the point of view of the world of innovation to which are attached values of empowerment and freedom, such choices are not morally acceptable; why should some have the chance to go to school and not others? Each logic drawing its reference from its own value system, and these systems being exclusive of each other, there is no real meeting point through which one world can influence the other. And value systems that do not meet tend to become value systems which are judgemental of each other:

At school, one learns to become a big person. A big person is what? It is someone that works in an air-conditioned office. At home, one learns what you need to be able help the family survive tomorrow, when your parents aren't there any longer.

What emerges therefore is an inherent uselessness of knowledge produced in one world when it is transferred to the other - 'Children who go to school, no longer want to grow crops.' Here we stress that it is not a lack of knowledge that creates an incapacity to use your abilities for the good of society, but the irrelevance of such knowledge to the world in which it is to be applied. In other words, each world sees the knowledge of the other as useless because they each employ their own value systems and attach very different values to different types of knowledge.

From the point of view of putting in place policies for Education for All - predominantly a view of education relevant to the world of innovation - it is imperative to address the fundamental chasm between these radically different value systems. In order to be effective, those implementing these policies must begin to appreciate the knowledge base within the world of reproduction and how easy it is to misconstrue it as irrelevant when one belongs to the world of innovation. Given the dominance and power inherent in the world of innovation, it is only through actively engaging people living in extreme poverty in dialogue that we can begin to break down these silos and really understand what Education for All means for the whole of society.

Participants in the research were acutely aware of the tensions between these two worlds. They expressed concern that the modern education system in Burkina Faso often represents the antithesis of the sorts of traditional education they value and undermines the importance of hard physical work. They spoke of the enormous efforts to educate their children which remained largely unrecognized by the formal education system. As one participant put it:

Traditional knowledge and specialized knowledge should complement each other. Unfortunately, however, there is a tension between them. Those who have been to school take one side and think they are always right. And those who haven't been to school take their side and believe that the others have made a mistake and are wrong. But I think this is unfortunate because we have to pull all this knowledge together. If not, then those who have learned traditional ways and those who learned from school can never be reunited.

Importantly, however, participants also gave examples of their efforts to reconcile different types of knowledge and to keep their children grounded in both worlds:

I have chosen to send my children to school but it is not school alone that will enable them to succeed. I send my sons to sell things during the holidays. That experience will also give them opportunities; that way they understand that it is not only school that gives success. Even if they don't succeed at school they will have other ways of making ends meet. 
What our parents bequeathed to us as knowledge and what we learned at the school, I can say often do not go hand in hand - but it often requires work to reconcile these two forms of knowledge so that in the end there is no contradiction. Because what I learn at school, I can say is beneficial for me, the knowledge I gained from my parents I consider as traditional, also beneficial for me. I always think about how best to combine these types of knowledge and move forward.

\section{Discussion and Conclusion}

The process of action research and the seminar which drew it all together developed a shared vision of the meaning of Education for All, what prevents it and what might enable it to be attained. The question of what is knowledge-its acquisition and transmission, its underlying values and its usefulness - brings out the tensions within Burkinabe society as it struggles for harmony between community and global value systems and considers the meaning of Education for All. This observation is not new; the tension between local and global knowledge has been examined in previous research and certain key lessons have been drawn (Tourneaux, 2011). Such work has shown, for example, that the exclusive use of French penalizes those children whose parents cannot speak it. Equally that developing appropriate educational curricula is not just a question of taking educational programmes conceptualized in French or English and translating them into African languages, but ensuring that languages and local knowledge are integrated into the educational system so that it is possible to bring about endogenous social change. Nonetheless, significant challenges remain which typify the difficulties faced by Burkina Faso in implementing the Millennium Development Goal of Education for All. The persistence of these challenges makes it imperative to continue to pay attention to them.

One way of approaching and beginning to understand this tension with respect to education is to consider the social representations at work - the ways in which society communicates and teaches about the social, material and ideological environment (Jodelet, 1984). Our analysis shows that the possible tensions relating to different understandings of knowledge and educational success arise out of an incompatibility between systems which renders them entirely exclusive of each other. In addition, such analysis allows us to specify the nature of this incompatibility in relation to education and to think about its consequences.

In our view, the failure to effectively implement policies offering Education for All is linked to a presupposition, itself dependent exclusively on the social representations contained in the world of innovation, of society's responsibility to eradicate ignorance. The reality is, however, that such policies are not responding to ignorance but to knowledge. Yet, since the exclusivity of these worlds means that where one has knowledge in one world it is not recognized as valid in the other, these different types of knowledge remain unappreciated, unless there is commitment to reconcile them.

The participatory research reported on here demonstrates one approach towards achieving a degree of reconciliation between these different worlds. We have seen that the original principle which underpins and gives meaning to basic knowledge is the capacity of such knowledge to nurture a sense of belonging. In a cultural context where the community is paramount and gives meaning to the individual, it is these social ties which support the transmission of knowledge. Speaking of our cultural activities in rural and urban environments, many parents told us, 'it is good what you are doing, you reunite children and with that they learn.'

Educational for All appears to depend on several things. Bringing about educational policies rooted in shared knowledge and understanding necessitates a permanent dialogue between the family, the community and the school. This must ensure the involvement of everyone and should recognize that each child belongs to a diversified and expansive educational community encompassing different conceptualizations of educational success. The methodology presented in this chapter allows the generation of shared knowledge grounded in the lived experience and values of those 
living in extreme poverty. The process of reconciling different types of knowledge helps bridge the gap between the world of reproduction (that of tradition) and the world of innovation (that of modernity).

To put in place educational policies which are for everyone and adapted to their environments, it is necessary to start from appreciating the knowledge base of any community and not from the presumption of ignorance. Facilitating the sharing and uniting of different types of knowledge provides the basis for designing an educational system that is really for everyone. The ways in which we have worked through these pilot projects to ensure dialogue between the environment and school in order to generate a common educational project could be replicated in other contexts.

From the perspective of international institutions that make their case on the evidence available, it should be remembered that those in extreme poverty have high expectations of school because it offers the promise of social inclusion compared to a community which often alienates and excludes them. As one mother put it, 'I send my children to school because I don't want them to lead the same life that I have known. If we are to respond to the expectations of populations who have been repeatedly socially excluded, schools with the mission of Education for All must support and strengthen learning about the dynamics of belonging and in this way satisfy the ambition of this mother.

The need for dialogue between the different actors within the educational community has to be integrated into global policies on Education for All, paying particular attention to strengthening cooperation between all its actors - between children, between teachers and pupils and between teachers and families. Building such cooperation requires each actor to recognize the contribution of the others within the educational community and to understand how these different contributions complement each other.

For researchers and universities, we learn that the concept of education has to be expanded to include work on understanding conceptualizations of basic knowledge and what constitutes educational success; being useful to oneself, to the family and having a sense of belonging to the community and to society. Researchers from the universities who participated in this process of understanding knowledge also questioned their own responsibilities concerning this quest for Education for All. As one explained,

We often think that if we listen carefully to what people tell us about their daily struggles, we can analyse their words and come up with some good solutions to present to those who have positions of responsibility: the government, policy makers, representatives of international organizations etc. But, the problem with this approach is that something is missing, we lose the opportunity to enable people to find their own solutions to these problems and so our research methods are inherently limited. A major challenge for us is to think about how we can work better with people living in extreme poverty across the world so that they discover and voice their own solutions.

For those who have faced the daily struggles of resisting extreme poverty, the experience of action research was enlightening, summarized here:

We knew that we had ideas and that these ideas are important for others. We have understood that understanding life enables us to change it. These words that have been said, they remind us of what we know, but we have forgotten and now we can apply this knowledge and the whole country can move forward.

Education clearly has the potential for alleviating extreme poverty in countries such as Burkina Faso in economic, social and political terms. Provided there is a supportive economic environment, it may widen opportunities and choices and increase financial capacity, thus improving the quality of people's lives. Equally, it can play a significant role in reducing social marginalization, giving people greater control over their lives and sustaining systems of good governance. As we have seen 
in this chapter, however, the capacity of education to enhance economic, social and human capital is contingent on education systems being relevant and appropriate to the context in which they are designed and implemented. Understanding where formal educational provision sits within the wider context of children and young people's lives; recognizing the importance of the learning that takes place outside of as well as within the school context; and being cognizant of the cultural norms, values and expectations of parents and the wider community are all vital in creating educational provisions which support economic, social and human development. As we have outlined here, such understanding comes from a continuous process of dialogue, interaction and mutual learning between educational structures and the wider communities they are intended to serve.

\section{Notes}

${ }^{1}$ This paper was originally published as part of the book Education, Poverty, Malnutrition and Famine (2014). London: Bloomsbury Academic. Revisions were made to suit the journal

${ }^{2}$ The findings presented in this chapter are from a project conducted by the ATD (Agir Tous pour La Dignity All Together in Dignity) Fourth World movement, which has worked in Burkina Faso for almost 30 years, striving to promote solidarity among those facing extreme poverty and exclusion ( http://www.atd-fourthworld. org/International-Movement-ATD-Fourth.html) . Our sincere thanks go to all those who took part in the action research project and who shared their experiences.

${ }^{3}$ The quotes used throughout the chapter are anonymized extracts taken from the action research which were filmed and used (with participants' permission) as prompts for discussion throughout the seminar in Ouagadougou.

\section{References}

ATD Fourth World (2004). How Poverty Separates Parents and Children: A Challenge to Human Rights. Méry-Sur-Oise: Fourth World Publications.

ATD Fourth World (2012). Guidelines for the Merging of Knowledge and Practices When Working with People Living in Situations of Poverty and Social Exclusion. Available at: http://www.atdfourthworld.org/ Guidelines-for-the-Merging-of.html [Accessed 18 June 2013].

Barbier, R. (1996). La Recherche Action. Paris: Economica, col. Anthropos.

Descartes, R. (1637). Discourse on Method. Vol. XXXIV, Part 1. The Harvard Classics. New York: P.F. Collier \&Son, pp. 1909-1914.

Freire, P. (1972). Pedagogy of the Oppressed. London: Penguin.

Freire, P. (1974). Education for Critical Consciousness. London: Continuum.

Jodelet, D. (1984). Représentations sociales: phénomènes, concepts et théorie. In: S. Moscovici, Psychologie sociale. Paris: PUF, pp. 357-378. (Trans: Social Representations: phenomena, concepts and theory In S. Moscovici, Social Psychology).

Tourneux, H. (2011). La transmission des savoirs en Afrique. Savoirs locaux et langues locales pour l'enseignement, Paris: Karthala (Trans: The transmission of knowledge in Africa. Teaching with local knowledge and local languages).

UNDP (2013). Human Development Report, Burkina Faso. Available at: http://hdrstats.undp.org/en/ countries/profiles/bfa.html [Accessed 19 June 2013].

United Nations (2000). Millennium Development Goals. Available at: http://www.un.org/ millenniumgoals/ [Accessed 18 June 2013].

United Nations (2013). We Can End Poverty 2015 Millennium Development Goals. Available at: http:// www.un.org/millenniumgoals/beyond2015-news.shtml [Accessed 15 July 2013].

Walker, R., Bantebya Kyomuhendo, G., Chase, E., Chouudhry, S., Gurbrium, E.L., Ødemel, I., Mathew, L., Mwiine, A., Pellissery, S. and Yan, M. (2013). Poverty in Global Perspective: Is shame a common denominator. Journal of Social Policy, 42(2), pp. 215-233.

World Food Programme (2013). Burkina Faso Overview. Available at: http://www.wfp.org/countries/ burkina-faso/overview [Accessed 18 June 2013]. 